\title{
Kontribusi Pertanian Berkelanjutan di Lahan Suboptimal Terhadap Aspek Lingkungan dan Sosial-ekonomi di Kecamatan Pulau Burung, Provinsi Riau
}

\author{
(Contribution of Sustainable Agriculture in Suboptimal Lands to \\ Environmental and Socio-economic Aspects in Pulau Burung District, \\ Riau Province)
}

\author{
Ika Zahara Qurani ${ }^{1 *}$, Sanudin ${ }^{2}$, Nurul Ihsan Fawzi ${ }^{1}$ \\ (Diterima Juni 2021/Disetujui Januari 2022)
}

\begin{abstract}
ABSTRAK
Kompleksitas dan kondisi alamiah lahan suboptimal sering kali membuat lahan tersebut kurang dimanfaatkan dan bahkan ditinggalkan sebagai lahan tidur ataupun dieksploitasi hingga menimbulkan masalah lingkungan. Padahal, lahan suboptimal, termasuk gambut, dapat menjadi alternatif di tengah penurunan luas lahan subur per kapita untuk pertanian. Penelitian ini bertujuan untuk menilai kontribusi pertanian berkelanjutan komoditas kelapa di lahan gambut pada aspek lingkungan dan sosial ekonomi di Kecamatan Pulau Burung, Kabupaten Indragiri Hilir, Provinsi Riau. Data untuk aspek lingkungan berasal dari data sekunder yang disediakan perusahaan setempat. Perolehan data untuk aspek sosial ekonomi menggunakan diskusi kelompok terarah (DKT) di lima desa melalui wawancara semi-terstruktur dengan 29 warga dengan berbagai latar belakang. Hasilnya, praktik pertanian di daerah ini dapat dikatakan berkelanjutan berdasarkan indikator manajemen pengairan. Dampak lingkungan sangat minimal, biodiversitas terjaga, dan laju subsiden sangat rendah di angka 1,7 cm per tahun. Untuk aspek sosial ekonomi dapat disimpulkan bahwa masyarakat menganggap aspek lingkungan dan sosial terjaga dengan baik. Merujuk pada hasil KDT, praktik pertanian, pengendalian kebakaran lahan, akses pangan, pengelolaan limbah, dan akses air merupakan aspek yang dinilai memadai bagi masyarakat. Sebaliknya, tata kelola lahan mendapat skor terendah karena kesulitan dalam pengurusan sertifikat lahan.
\end{abstract}

Kata kunci: gambut, lahan suboptimal, manajemen air, pertanian berkelanjutan

\section{ABSTRACT}

The circumstance of suboptimal land, due to its complex and often difficult nature, is either under-utilized and becomes abandoned space or over-utilized and generates environmental problems. In fact, suboptimal land, including peatlands, can be an alternative amid the decreasing area of arable land per capita for agriculture. This study aims to assess the contribution of sustainable agriculture for coconut commodities in the peatlands area, Pulau Burung District, Indragiri Hilir Regency, Riau Province. Data on environmental aspects were obtained from secondary data provided by the local company. Data on socio-economic aspects were obtained using focus group discussions (FGD) in five villages through semi-structured interview to 29 residents from various backgrounds. As a result, agricultural practices in this area can be deemed as sustainable based on water management indicators. The environmental impact is very minimal, biodiversity is preserved, and the subsidence rate is very low at $1.7 \mathrm{~cm}$ per year. In terms of socio-economic aspect, it can be concluded that the community perceives the environmental and social aspects are well maintained. Referring to the results of the FGD on agricultural practices, land fire control, food access, waste management, and water access are aspects that are considered adequate for the community. In contrast, land governance scored the lowest due to the difficulties in obtaining land certificates.

Keywords: peatland, suboptimal land, sustainable agriculture, water management

\section{PENDAHULUAN}

Pertambahan penduduk dunia membutuhkan lahan pertanian yang lebih banyak untuk mencukupi

1 Tay Juhana Foundation, Jln. Rawa Bebek Utara No. 26 Penjaringan, Jakarta 14440

2 Balai Litbang Teknologi Agroforestri Ciamis, Jl. Raya Ciamis-Banjar Km. 4. Ciamis 46201

* Penulis Korespondensi:

E-mail: zara@tayjuhanafoundation.org kebutuhan pangan (Lanz et al. 2018). Akan tetapi, jumlah luasan lahan subur per kapita dunia semakin menurun dari 0,361 ha per orang pada tahun 1961 menjadi hanya 0,184 ha pada tahun 2018 (World Bank 2018a). Di Indonesia sendiri angkanya bahkan jauh lebih sedikit, pada tahun 1961 lahan subur per kapitanya hanya 0,2 ha per orang dan menurun drastis menjadi 0,098 pada tahun 2018 (World Bank 2018b). Hal ini banyak disebabkan karena konversi lahan pertanian menjadi lahan terbangun (perumahan, pabrik, dan jalan) yang semakin meningkat. Laju konversi 
lahan pertanian mencapai $140.000-187.000$ ha per tahun, terutama di lahan-lahan pertanian subur di Pulau Jawa (Rondhi et al. 2019; World Bank 2008).

Penduduk Indonesia pada tahun 2020 berjumlah 270 juta jiwa, meningkat 32,56 juta jiwa dalam 10 tahun terakhir (BPS 2021). Untuk memenuhi kebutuhan pangan penduduk yang selalu bertambah, diperlukan penambahan lahan pertanian di tengah penurunan luasan lahan subur. Ketika lahan subur semakin sedikit, jenis lahan suboptimal, seperti lahan rawa, gambut, atau lahan kering, dapat dimanfaatkan untuk pertanian. Dengan penentuan karakteristik tanah yang sesuai, lahan gambut yang kurang subur dapat menjadi alternatif bagi pertanian berkelanjutan untuk menopang produksi pangan serta meningkatkan kesejahteraan masyarakat (Kang et al. 2013; Lakitan, 2014; Preissel et al. 2017; Surahman et al. 2018).

Selaras dengan gagasan tersebut, penelitian ini ingin mengidentifikasi praktik pertanian berkelanjutan di lahan suboptimal, khususnya lahan gambut. Selama ini, pertanian di lahan gambut terkenal dengan praktik yang tinggi emisi dan tidak berkelanjutan. Praktik pertanian di lahan gambut membutuhkan penurunan tinggi muka air tanah agar tanaman dapat bertumbuh. Sering kali, penurunan muka air tanah menyebabkan gambut menjadi kering, yang memicu terjadinya subsiden dan kebakaran lahan (Buschmann et al. 2020; Evans et al. 2019; Konecny et al. 2016; Wijedasa et al. 2018). Padahal lahan gambut pada saat ini memegang kunci produk-produk pertanian, seperti minyak sawit, sagu, dan produk hortikultura (Surahman et al. 2018; Uda et al. 2017).

Salah satu produk unggulan di Kabupaten Indragiri Hilir, Provinsi Riau adalah kelapa dan sebagian besar lahan yang didominasi gambut telah ditanam kelapa oleh penduduk lokal (Direktorat Jenderal Perkebunan, 2019; Akmal et al. 2020). Dimensi praktik pertanian kelapa berkelanjutan, yaitu lingkungan, sosial, dan ekonomi, telah menjadi bagian dari pertanian kelapa di daerah ini sehingga mampu bertahan lebih dari 30 tahun dan akan terus berproduksi. Penelitian ini bertujuan untuk menganalisis kontribusi praktik pertanian pada ekosistem lahan gambut terhadap aspek lingkungan dan sosial-ekonomi.

\section{METODE PENELITIAN}

\section{Lokasi Penelitian}

Penelitian ini dilakukan di Kecamatan Pulau Burung, Kabupaten Indragiri Hilir, Provinsi Riau, dengan luas $538.33 \mathrm{~km}^{2}$ dan terdiri atas 14 desa (Gambar 1). Terdapat lima desa yang menjadi lokasi penelitian di Kecamatan Pulau Burung. Desa-desa tersebut adalah Desa Binangun Jaya atau SP-9, Desa Manunggal Jaya atau SP-3, Desa Suka Jaya atau SP10, dan Desa Bangun Harjo Jaya atau SP-4. SP merupakan sebutan untuk "Satuan Permukiman" yang
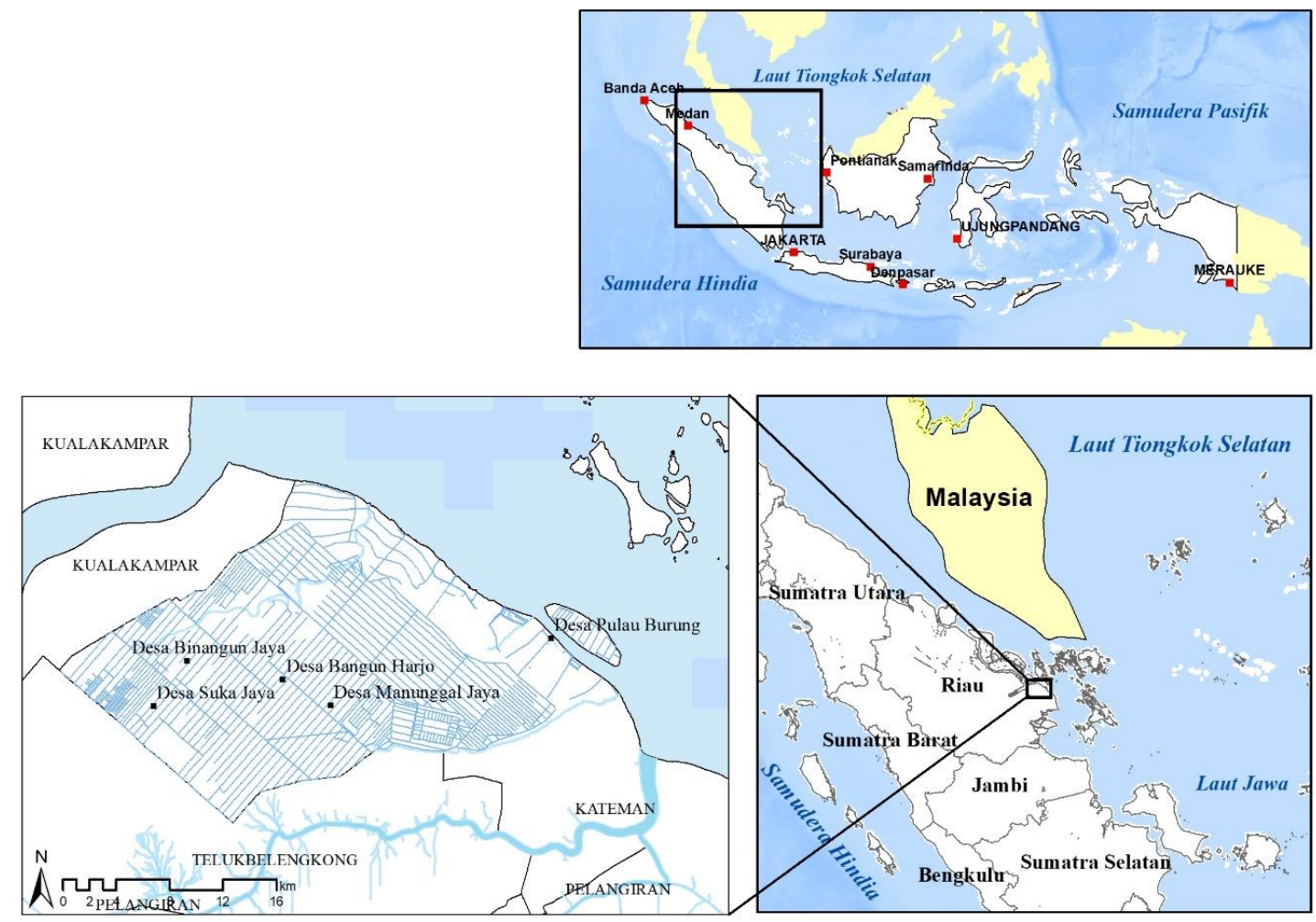

Gambar 1 Peta lima desa lokasi penelitian di Kecamatan Pulau Burung, Kabupaten Indragiri Hilir (Tay Juhana Foundation 2021). 
dibentuk sebagai bagian dari program transmigrasi dan sekarang telah mendapatkan status administrasi menjadi desa.

Secara historis, Pulau Burung merupakan lokasi program transmigrasi pada tahun 1986. Sesuai dengan Instruksi Presiden No. 1/1/1986, Sambu Group telah diberi mandat untuk membangun perkebunan inti demi mendukung program ketahanan pangan dan bertindak sebagai mitra pemerintah dalam mengelola Perkebunan Inti Rakyat-Trans (PIR-Trans). Melalui skema PIR-Trans ini, ratusan transmigran pada waktu itu diberikan rumah dan kavling perkebunan untuk budi daya kelapa dan komoditas lain. Pengelolaan PIRTrans dilakukan oleh perusahaan Sambu Group, yang secara bersamaan membangun industri pengolahan kelapa dan sistem tata air di gambut yang dikenal dengan "trio tata air." Trio tata air merupakan metode manajemen air perkebunan kelapa di Pulau Burung yang memelihara agar air di gambut tidak kering untuk mendukung pertumbuhan kelapa tanpa merusak gambut.

\section{Waktu dan Metode Pengumpulan Data}

Penelitian ini dilakukan pada bulan Juli 2019. Analisis praktik pertanian berkelanjutan menggunakan data-data sekunder dari kantor desa dan perusahaan lokal, terutama laporan teknis mengenai trio tata air dan dampaknya pada kondisi ekosistem dan kegiatan pertanian. Hasilnya dijelaskan secara deskriptif tentang sintesis sistem yang membuat pertanian di lahan gambut berkelanjutan.

Penilaian kontribusi pertanian berkelanjutan terhadap aspek lingkungan menggunakan dua indi-kator utama, yaitu keanekaragaman hayati dan sub-siden (amblesan tanah akibat hilangnya air yang meno-pang struktur tanah). Parameter tersebut dianalisis dari data yang diperoleh dari Sambu Group, karena memiliki data tahunan sejak awal pemanfaatan gambut untuk perkebunan kelapa pada tahun 1986. Untuk data subsiden, pengukuran dilakukan pada 4 titik pengukuran subsiden $(\mathrm{N}=4)$ yang diukur pada tahun 1986-2019. Subsiden merupakan penurunan muka tanah gambut terhadap titik referensi dan diukur dengan tiang besi yang ditancapkan di gambut hingga menyentuh tanah mineral. Pengukuran subsiden dilakukan setiap enam bulan sekali oleh Sambu Group.

Data utama penilaian kontribusi pertanian berkelanjutan terhadap aspek sosial ekonomi diperoleh dari Diskusi Kelompok Terarah (DKT) yang dilakukan di lima desa lokasi penelitian di Kecamatan Pulau Burung. Pemilihan responden menggunakan purposive sampling di mana peneliti dapat menentukan hal apa saja yang ingin diketahui, serta kriteria responden yang memiliki kapasitas untuk menjawab pertanyaan dalam wawancara (Bernard 2002; Tongco 2007). Responden yang dipilih berasal dari kelompok masyarakat yang bervariasi agar meng-hasilkan pendapat yang lebih holistik, di mana tiap kelompok diskusi dapat berjumlah 5-15 orang (FAO 2011). Karena keterbatasan waktu dan seluruh masyarakat di desa aktif bekerja, DKT di setiap desa hanya dihadiri oleh 6 responden dari latar belakang petani (memiliki lahan minimal $0,5 \mathrm{ha}$ ), petani yang tidak memiliki lahan, petani perempuan, tokoh masyarakat, pedagang, dan pemuda (umur 15-30 tahun). Dengan demikian, total responden dalam penelitian ini adalah 29 orang $(\mathrm{N}=29)$, dari desain awal 30 responden (1 responden tidak hadir dalam DKT).

Identifikasi dampak sosial ekonomi yang dilakukan dalam DKT adalah dengan diskusi kelompok terarah tentang 10 indikator keberlanjutan pertanian di lahan gambut melalui wawancara semi-terstruktur. Pendekatan ini sering kali dipakai dalam penelitian lingkungan kualitatif karena sesuai dengan prinsip partisipasi masyarakat untuk membahas suatu permasalahan (Ochieng et.al. 2018).

\section{Metode Analisis Data}

Hasil yang diperoleh melalui kuesioner ini diolah dengan skala tipe Likert yang banyak digunakan di penelitian sosial (Joshi et al. 2015; Koop et al. 2017). Jawaban responden kemudian diberikan skala pada tiap pertanyaan. Nilai masing-masing skala berkisar dari 1 (Sangat Negatif), 2 (Negatif), 3 (Positif), hingga 4 (Sangat Positif). Skala tersebut kemudian diambil nilai rata-rata dan dikonversi menjadi skor dengan kategori 0,0-1 (Sangat Buruk), 1,1-2 (Buruk), 2,1-3 (Baik), dan 3,1-4 (Sangat Baik) untuk menilai besaran dampak pertanian berkelanjutan.

\section{HASIL DAN PEMBAHASAN}

\section{Sistem Pertanian di Pulau Burung}

Dilihat dari kondisi biofisik, kondisi tanah di Pulau Burung merupakan jenis gambut tropis yang membuatnya sulit digunakan sebagai media bercocok tanam. Hambatan utama terletak pada tanahnya yang berporositas tinggi yang membuat banyak resapan air. Akibatnya, terjadi evaporasi yang berlebih, terutama pada saat musim kemarau. Karakteristik tanahnya merupakan gabungan dari lahan rendah, lahan datar, dan lahan basah. Tingkat kematangan tanah berkisar antara saprik dan hemik sehingga tanaman budi daya tetap bisa tumbuh. Rata-rata elevasi lahan adalah 12,5 $\mathrm{m}$ dengan kemiringan rata-rata 8 persen. Sementara itu, daerah basah-lembap ini memiliki tingkat curah hujan tahunan rata-rata lebih dari 2000 mm, meskipun hanya tercatat $1255 \mathrm{~mm}$ per tahun pada tahun 1997 (Sambu Group 2015).

Pada tahun 1980-an, tim ahli dari Sambu Group, tokoh masyarakat, pemerintah, dan pemangku kepentingan lainnya telah bekerja sama untuk melakukan studi untuk membangun sistem air yang cocok dengan kondisi ekosistem yang ada (Sambu Group 2015 ). Karakter wilayah Pulau Burung sangat berpotensi untuk menampung air tawar. Lahannya yang datar dan rendah, tingkat curah hujan tinggi, ditambah dengan keberadaan Bukit Barisan di Sumatera Barat yang membuat air di daerah bukit mengalir ke Indragiri Hilir. 
Berdasarkan hasil DKT, sistem air yang dibangun bukanlah sistem drainase tradisional yang mengeringkan gambut, melainkan mengatur air untuk mendukung pertanian kelapa yang berkelanjutan. Hal ini dikarenakan manajemen hidrologi merupakan kunci utama dalam menentukan tingkat keberlanjutan pertanian di lahan gambut (Wijedasa et al. 2017).

Teknik yang digunakan terutama terdiri atas sistem air yang terintegrasi atau dikenal dengan "Trio Tata Air." Sistem ini terdiri atas kanal-kanal, tanggul, bendungan, dan pintu air (Gambar 2). Fungsi utama sistem ini antara lain mengatur ketersediaan air pada musim yang berbeda-beda, mendukung pertumbuhan kelapa yang produktif secara agronomi, mencegah kebakaran, meminimalisir subsiden, dan menopang transportasi air. Trio tata air menjaga kelembapan dalam tanah gambut sehingga api sulit menyebar. Kandungan air dalam tanah yang terkendali juga terbukti memperlambat laju subsiden lahan serta mengurangi risiko banjir dan inundasi (penggenangan area pertanian) di area sekitarnya.

Trio tata air didukung oleh tiga sistem utama, yaitu: kanal reservoir, tanggul, dan bendungan yang disertai pintu air. Kanal reservoir di Kecamatan Pulau Burung memiliki total panjang kanal primer, sekunder, kolektor, dan tersier berjumlah lebih dari $4.000 \mathrm{~km}$. Kanal-kanal tersebut mampu menjaga ketersediaan $45 \mathrm{~m}^{3}$ volume air tawar sepanjang tahun (Tabel 1). Kanal reservoir primer terutama berfungsi sebagai saluran air untuk mendukung metode transportasi utama di daerah setempat, seperti yang dapat dilihat dari dimensi kanal yang muat dan bisa dilalui oleh lebih dari satu kapal. Dimensinya yang besar juga berfungsi sebagai penampung luapan air dari kanal sekunder. Kanal reservoir sekunder dirancang untuk mengatur ketinggian air dalam jaringan dengan menyimpan luapan dari saluran tersier. Kanal reservoir sekunder juga mengatur level air tanah agar tidak turun terlalu rendah, tetapi juga tidak membebani sistem akar tanaman. Kanal dengan dimensi terkecil, yaitu kanal tersier, merupakan kanal yang paling banyak jumlahnya dengan fungsi utama untuk menjaga ketinggian air tanah dalam plot lahan. Kanal tersier juga berfungsi untuk menyimpan kelebihan air akibat hujan. Sebagai bagian dari sistem air yang terintegrasi, struktur hidrolik kanal dirancang untuk membantu mengelola aliran air yang merupakan bagian dari jaringan transportasi. Struktur ini mengatur kedalaman air, debit, dan kemiringan air di kanal sehingga risiko erosi dapat diminimalisir.

Tanggul dibuat oleh komposisi alami, seperti tanah yang dipadatkan, batang pohon kelapa, tempurung kelapa, dan serat. Tanggul-tanggul ini dirawat secara berkala dengan frekuensi berbeda bergantung pada usia tanggulnya. Desain tanggul dibuat agar dapat menahan tekanan dengan lebih baik dan bertahan lebih lama karena pada tanggul tersebut dibangun titiktitik penting di mana pengaturan permukaan air bisa berjalan secara efektif. Untuk bendungan dengan pintu air, peran integral dua komponen ini pada dasarnya bertindak sebagai pengatur ketinggian air dan juga sebagai lokus kendali retensi air. Pintu air mengontrol distribusi air ke area yang berbeda dan memastikan pasokan air yang memadai pada tingkat yang dibutuhkan untuk menjaga keseimbangan antara

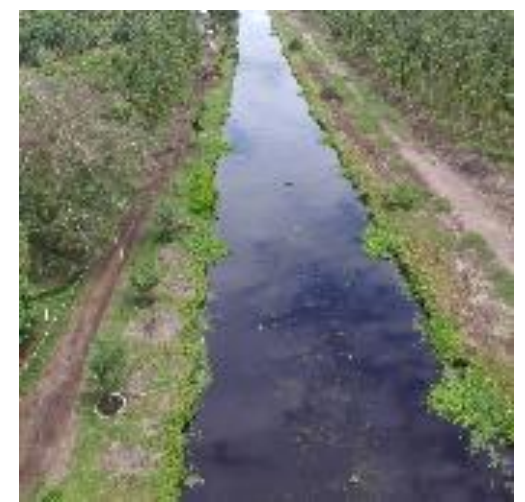

(a)

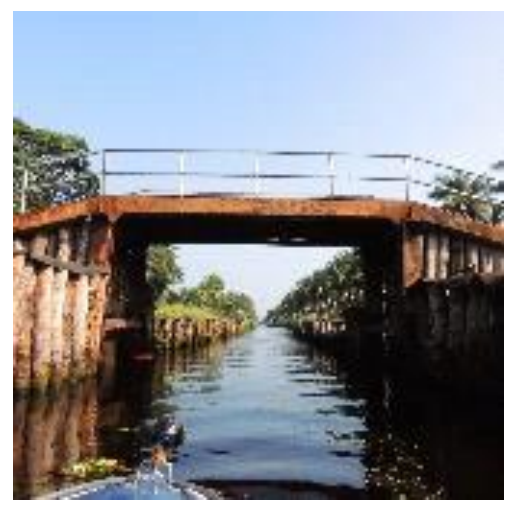

(b)

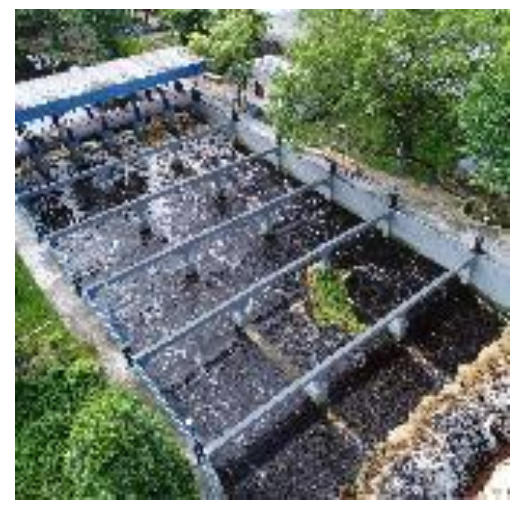

(c)

Gambar 2 Kanal utama, tanggul yang terbuat dari bahan organik, dan pintu air utama di daerah pesisir Pulau Burung Riau (Tay Juhana Foundation 2021).

Tabel 1 Jenis dan dimensi kanal-kanal di Kecamatan Pulau Burung, Riau

\begin{tabular}{lcccc}
\hline Jenis Kanal & Panjang $(\mathrm{km})$ & Lebar $(\mathrm{m})$ & Kedalaman $(\mathrm{m})$ & Volume $\left(\mathrm{m}^{3}\right)$ \\
\hline Primer & 99,5 & 26 & 5 & 15.204 .351 \\
Semi-primer & 74,0 & 15 & 4 & 3 \\
Kolektor & 30,0 & 10 & 3 & 30.692 .542 \\
Sekunder & 928,0 & 6 & 3 & 1.006 .000 \\
Semi-sekunder & 165,6 & 5 & 1 & 46.902 .893 \\
Tersier & 2719,0 & 1 & & \\
Jumlah & 4016,1 & & & \\
\hline
\end{tabular}

Sumber: Sambu Group (2015). 
produktivitas kelapa, kelembapan tanah gambut, dan tinggi muka air tanah.

Selain penanganan aspek lingkungan di gambut dengan manajemen air, praktik pertanian juga menjadi perhatian di perkebunan kelapa. Skema PIR-Trans dengan dukungan sistem trio tata air mampu mempertahankan produksi kelapa yang tinggi. Jenis kelapa yang digunakan adalah kelapa hibrida. Pada tahun 2015, produksi kelapa mencapai 5.345 butir kelapa per hektar (Pasaribu et al. 2016), namun menurun menjadi 4.569 butir kelapa per hektar pada tahun 2018 akibat variasi musim (Sambu Group \& IPB, 2019). Penurunan jumlah produksi kelapa pada kebun plasma dengan skema PIR-Trans ini juga dialami oleh kebun inti yang dikelola langsung oleh Sambu Group, di mana produksi tahun 2018 adalah 4.500 butir kelapa per hektar. Hasil produksi kelapa tersebut didapatkan dengan sistem jarak tanam $7 \mathrm{~m} \times 10,42 \mathrm{~m}$ dengan empat persegi panjang yang memberikan jumlah pohon standar adalah 272 pohon per hektar. Sela antarpohon kelapa juga dimanfaatkan untuk ditanam nanas secara tumpang sari untuk meningkatkan pendapatan.

Hasil studi juga menemukan bahwa gambut di wilayah studi memiliki kapasitas tukar kation (KTK) yang tinggi berkisar antara 271,2 hingga 1.170,4 me per $\mathrm{kg}$. Meskipun memiliki KTK yang tinggi, tanah ini memiliki kejenuhan basa yang rendah yang mendorong unsur hara yang rendah di dalam tanah. Metode termurah untuk memperbaiki tanah adalah dengan membakar lahan untuk persiapan atau perawatan lahan kebun kelapa. Praktik membakar lahan tersebut tidak berkelanjutan. Solusi yang digunakan adalah dengan pemakaian pupuk organik yang mampu meningkatkan kesuburan tanah gambut melalui peningkatan kemasaman tanah. Pupuk organik ini dikenal dengan nama BioPeat, yang merupakan produk kerja sama pengaplikasian pupuk organik antara Sambu Group dan Badan Pengkajian dan Penerapan Teknologi (BPPT). Pada dasarnya, BioPeat digunakan untuk meningkatkan tingkat $\mathrm{pH}$ tanah. Sambu Group memiliki fasilitas untuk memproduksi BioPeat dalam skala besar dengan menggunakan campuran inokulan dan limbah nanas. Inokulan adalah hasil fermentasi bentuk padat dari jaringan yang diambil dari bahan BioPeat (contohnya, limbah organik nanas) yang ditambahkan Trichoderma sp. Metode kultur jaringan di laboratorium juga digunakan untuk terus meningkatkan inokulan biopeat. BioPeat juga dapat digunakan sebagai pupuk organik bersama VRM XLR8. Pupuk hayati BioPeat ini digunakan oleh petani untuk mengembangkan tanaman hortikultura, seperti tanaman cabai, sawi, kacang panjang, mentimun, melon air, dan jagung.

\section{Kontribusi Praktik Keberlanjutan Terhadap Aspek Lingkungan}

Keanekaragaman hayati, spesies flora dan fauna yang ada di kawasan ini cukup beragam. Di dalam perkebunan seluas 22,650 ha, terdapat lahan yang dialokasikan khusus oleh perusahaan (Sambu Group) untuk konservasi seluas 324 ha dengan flora dan fauna yang dimonitor oleh tenaga ahli dari perusahaan secara berkala. Dalam kawasan konservasi ini, tercatat ada beragam jenis spesies termasuk yang ada di dalam buku daftar merah International Union for Conservation of Nature (IUCN) dan dilindungi UU No.7/1999 tentang Pengawetan Jenis Tumbuhan dan Satwa, di antaranya, meranti (Shorea sp.), salak hutan (Salacca sp.), palem merah (Cyrtostachys lakka), dan banyak jenis burung (Falco peregrinus, Haliastur indus, Spizaetus cirrhatus, Elanus caeruleus, Pernis ptilorhynchus, Halcyon smyrnensis, Halcyion chloris, Anthracoceros malayanus, Anthracoceros albirostris, Leptoptilos javanicus, Sterna hirundo, Leptocoma calcostetha, Anthreptes singalensis, Anthreptes malacensis, Llepptocoma sperata, Cinnyris jugularis, Rhipidura javanica, dan Gracula religiosa). Keanekaragaman hayati ini tidak hanya di kawasan konservasi, tetapi jugan di areal perkebunan kelapa inti dan plasma. Terdapat larangan untuk memburu dan menebang pohon yang dilindungi sehingga keanekaragaman hayati yang ada tetap terjaga dan berkontribusi secara langsung pada produktivitas kelapa dengan membantu proses penyerbukan.

Di samping keanekaragaman hayati, faktor lain yang menjadi indikator keberlanjutan di lahan gambut adalah laju subsiden (Uda et al. 2017). Berdasarkan hasil pengukuran subsiden oleh Sambu Group, sistem trio tata air telah berkontribusi positif terhadap tingkat subsiden dengan meminimalkan laju penurunan tanah tahunan hanya $1,7 \mathrm{~cm}$ per tahun, atau $54,1 \mathrm{~cm}$ selama 32 tahun (Fawzi et al. 2020). Gambar 3 menunjukkan perbedaan laju subsiden dari praktik pertanian di Pulau Burung dan praktik lain di lokasi lahan gambut berbeda.

Dengan mekanisme trio tata air, laju subsiden setelah pembukaan lahan tercatat jauh lebih lambat (hanya $3,3 \mathrm{~cm}$ ) dibanding tingkat subsiden drainase konvensional yang bisa mencapai $75 \mathrm{~cm}$ di tahun pertama pemanfaatan gambut (Hooijer et al. 2012). Hasil subsiden di Pulau Burung juga berbeda jauh dibanding penelitian Wösten \& Ritzema (2001), di mana rerata subsiden tahun pertama mencapai $47 \mathrm{~cm}$. Hasil ini menunjukkan bahwa keberadaan sistem trio tata air yang membuat air tetap tersedia di kanal reservoir membuat tingkat oksidasi gambut rendah; berkontribusi terhadap rendahnya subsiden dan emisi karbon. Penelitian yang dilakukan oleh Fawzi et al. (2021) mengkonfirmasi keberadaan trio tata air mampu meminimalkan titik api dan kebakaran lahan gambut.

\section{Kontribusi Praktik Berkelanjutan Terhadap Aspek Sosial Ekonomi}

Mayoritas warga di Pulau Burung merupakan keturunan Jawa yang mengikuti program transmigrasi pemerintah ke Indragiri Hilir. Pada tahun 1980an, pemerintah memberikan lahan pertanian kepada transmigran seluas seluas \pm 2 hektar serta lahan untuk pekarangan dan perumahan seluas $\pm 0,5$ hektar. Kini, 


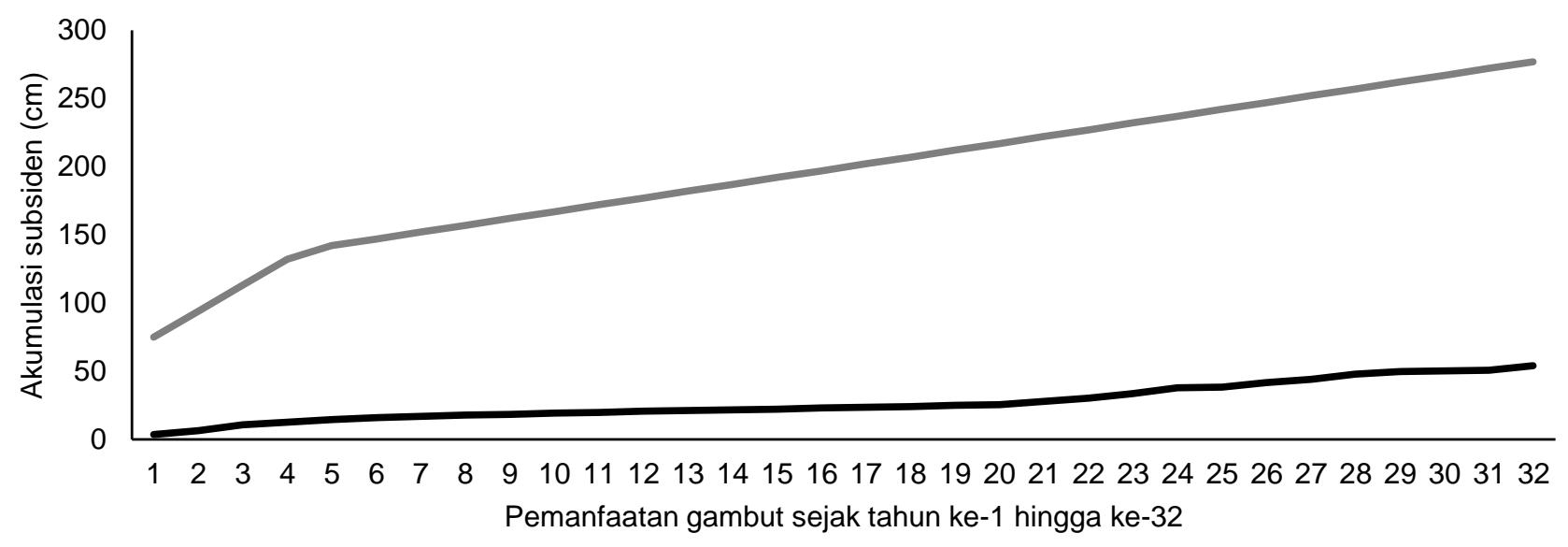

Pertanian dengan pengeringan gambut $\longrightarrow$ Pertanian kelapa di Pulau Burung dengan sistem tata air

Gambar 3 Grafik akumulasi subsiden di area perkebunan kelapa Kecamatan Pulau Burung dan subsiden di area gambut lainnya di Riau dikutip dari Hooijer et al. (2012).

pertanian di daerah tersebut telah berkembang setelah didukung oleh pengolahan kelapa yang lengkap dari hulu ke hilir, serta kanal-kanal yang digunakan sebaga irigasi dan transportasi air. Keberadaan komponen ini telah menjadikan lahan gambut menjadi subur dan mampu menumbuhkan berbagai tanaman perkebunan dan pertanian.

Berdasar hasil DKT diketahui bahwa secara umum masyarakat memiliki pendapat yang cenderung positif terhadap kondisi sosial dan ekonomi serta pengelolaan lingkungan di wilayah Pulau Burung. Persepsi positif oleh masyarakat disebabkan oleh peningkatan kesejahteraan dan kestabilan penghasilan yang cukup untuk kebutuhan dasar dan kebutuhan lainnya. Sistem pertanian kelapa yang berkelanjutan berkorelasi dengan kestabilan penghasilan keluarga. Hal ini disebabkan sebelum dibangunnya trio tata air untuk pengaturan air, perkebunan kelapa tradisional terkena dampak intrusi air laut. Hal ini menyebabkan penurunan produktivitas, mengurangi pendapatan petani (Hadi 2017), dan menyebabkan pelemahan rantai pasokan. Keadaan ini sesuai dengan teori yang disampaikan oleh Spangenberg (2005), bahwa keberlanjutan aspek sosial dapat diukur dari stabilitas penghasilan sebagai dampak dari pengelolaan sumber daya yang berkelanjutan.

Hasil penskoran disajikan pada Tabel 2. Dari tabel tersebut diketahui bahwa skor tertinggi terdapat pada aspek pengendalian kebakaran hutan dan lahan dengan nilai 3.3 (Sangat Baik). Skor sangat baik tersebut disebabkan oleh pengawasan yang ketat dari penegak hukum untuk mencegah kebakaran hutan dan lahan (karhutla). Selain itu, petani lokal memiliki kesadaran untuk tidak membakar lahan dan mengaku telah meninggalkan metode bakar lahan ketika merawat kebun kelapa atau membuka ladang. Walaupun metode tebang dan bakar dikenal sebagai cara paling murah untuk membuka lahan dan menyuburkan tanah, terutama di tanah yang masam, para petani memahami dampak negatif pembakaran tersebut. Terlebih lagi mereka mengatakan sangat takut pada penegakan hukum karhutla yang semakin ketat.

Skor untuk aspek ketahanan pangan juga cukup tinggi, yakni 3,0 (Sangat Baik). Hal ini dikarenakan kemudahan masyarakat mengakses sumber pangan, banyak masyarakat yang memiliki kebun sendiri, serta masih kuatnya budaya saling membantu antarwarga dalam proses pengadaan bahan makanan. Sementara itu, aspek kesehatan, pendidikan, dan infrastruktur mendapat skor yang tidak jauh berbeda karena ketiga hal tersebut cukup mudah dijangkau seperti adanya puskesmas, sekolah, dan infrastruktur publik lain di tiap desa. Meski demikian, tantangan lain muncul akibat biaya transportasi boat yang tinggi yang menyulitkan mobilitas warga ke luar kecamatan.

Kondisi ekonomi mendapat skor yang baik. Pada saat KDT dilakukan, harga kelapa sekitar Rp1.700 per buah, artinya petani kelapa di Pulau Burung pada saat itu mampu menjual hasil produksinya dengan harga sekitar Rp6,92-7,76 juta per hektar/tahun. Rata-rata, seorang petani kecil yang memasok kelapa ke pabrik pengolahan memiliki 3 hektar lahan, yang berarti menerima pendapatan tahunan dari kelapa sebesar Rp20,7-23 juta (Pasaribu et al. 2016; Sambu Group \& IPB, 2019). Meskipun angka ini di bawah rata-rata pendapatan tahunan dalam skala nasional maupun kabupaten, petani dapat melakukan pekerjaan tambahan (misalnya sebagai karyawan perusahaan, pedagang, dan buruh) di luar musim tanam dan panen kelapa yang berlangsung tiga bulan. Berdasarkan hasil wawancara, sebagian besar rumah tangga memiliki banyak sumber mata pencaharian selain bertani. Pendapatan yang stabil juga memungkinkan petani untuk meningkatkan kesejahteraan mereka. Penduduk sekarang memiliki tempat tinggal yang lebih permanen, sistem transportasi yang memungkinkan arus barang dan jasa, dan peningkatan kesempatan untuk mengejar pendidikan tinggi. 
Tabel 2 Hasil diskusi kelompok terarah (DKT) yang menunjukkan persepsi masyarakat terhadap kondisi lingkungan, sosial, dan ekonomi di lima desa yang menjadi lokasi penelitian

\begin{tabular}{|c|c|c|c|}
\hline Tema & Indikator & Skor & Penilaian \\
\hline Praktik Pertanian & $\begin{array}{l}\text { Sumber pendapatan, teknik pertanian di gambut, kualitas panen, dan } \\
\text { konflik pertanian yang minim. }\end{array}$ & 3 & Baik \\
\hline Kondisi Ekonomi & $\begin{array}{l}\text { Pendapatan cukup untuk kebutuhan dasar, memiliki tempat tinggal, } \\
\text { lahan, dan kendaraan. }\end{array}$ & 2,4 & Baik \\
\hline $\begin{array}{l}\text { Pengendalian } \\
\text { Karhutla }\end{array}$ & $\begin{array}{l}\text { Petani dan perusahaan tidak bakar lahan, ada tim pemadam } \\
\text { kebakaran, ada peralatan dan pemantauan. }\end{array}$ & 3,3 & Sangat baik \\
\hline Ketahanan Pangan & $\begin{array}{l}\text { Akses ke sumber pangan, keterjangkauan, nutrisi terpenuhi, dan } \\
\text { ketersediaan pangan. }\end{array}$ & 3 & Baik \\
\hline Limbah dan Polusi & $\begin{array}{l}\text { Indikasi pencemaran, pengelolaan dan pemanfaatan limbah, dan } \\
\text { dampak yang terasa. }\end{array}$ & 2,4 & Baik \\
\hline Kesehatan & $\begin{array}{l}\text { Akses ke fasilitas kesehatan, kelayakan sanitasi, program kesehatan } \\
\text { masyarakat, dan wabah penyakit. }\end{array}$ & 2,9 & Baik \\
\hline Pendidikan & $\begin{array}{l}\text { Akses ke pendidikan, tingkat pendidikan, keterjangkauan, kualitas } \\
\text { dan fasilitas pendidikan. }\end{array}$ & 2,9 & Baik \\
\hline Infrastruktur & $\begin{array}{l}\text { Akses ke sarana publik, jenis infrastruktur, kelayakan, dan } \\
\text { perawatan bangunan. }\end{array}$ & 2,8 & Baik \\
\hline Tata Kelola Lahan & $\begin{array}{l}\text { Kemudahan mengurus sertifikat lahan, tata kelola, penggunaan, dan } \\
\text { tingkat kepemilikan lahan. }\end{array}$ & 2 & Buruk \\
\hline Tata Kelola Air & $\begin{array}{l}\text { Akses ke air bersih, tata kelola, sumber air, penggunaan, konflik, dan } \\
\text { keterjangkauan. }\end{array}$ & 2,4 & Baik \\
\hline
\end{tabular}

Terkait masalah limbah dan polusi, masyarakat menyebutkan bahwa tidak ada indikasi pencemaran dari limbah pabrik. Indikator ini mendapat skor 2,4 (Baik) dalam konteks pengelolaan limbah di ruang lingkup industri pengolahan kelapa. Meski demikian, sampah rumah tangga merupakan limbah yang mendominasi kanal dan jalanan sebagai dampak dari pengolahan sampah yang tidak terpusat.

Tata kelola air mendapatkan skor penilaian Baik (2.4). Keberadaan trio tata air memastikan ketersediaan air di musim kemarau dan tidak terjadi banjir pada saat musim hujan. Hal yang menyebabkan skor lebih rendah adalah air yang ada merupakan air gambut dengan karakteristik warna hitam dan masam, tidak dapat digunakan sebagai air minum. Untuk mendapatkan air bersih untuk minum warga menampung air hujan serta membeli air mineral komersial. Akan tetapi, sejak tahun 2020 beberapa infrastruktur penyediaan air serta distribusi air mineral telah semakin berkembang sehingga situasi ini cukup merepresentasikan skor 2,4 (Baik) di bidang akses air.

Tata kelola lahan menjadi isu yang mempunyai skor terendah, yakni 2,0 (Buruk). Petani mengeluhkan ketidakjelasan persyaratan untuk mengurus sertifikat lahan, biaya tinggi, serta birokrasi yang panjang. Sementara itu, isu sengketa lahan tidak ditemukan karena batas kepemilikan lahan sudah cukup jelas.

\section{KESIMPULAN}

Pemanfaatan lahan suboptimal merupakan salah satu solusi untuk meningkatkan produksi pangan dalam mewujudkan visi ketahanan pangan nasional. Lahan gambut merupakan bagian dari lahan suboptimal yang di beberapa daerah memiliki karakter tanah yang cocok untuk pertanian. Jika dikelola dengan manajemen air yang efektif dan teknologi tanah yang tepat akan menjadi produktif dengan dampak lingkungan yang minimal. Penelitian ini mengemukakan dua indikator untuk mengukur kontribusi praktik pertanian pada ekosistem lahan gambut terhadap aspek lingkungan dan sosialekonomi. Kontribusi terhadap aspek lingkungan didukung oleh keberadaan aplikasi sistem pengelolaan air "trio tata air" yang mampu menahan laju subsiden, menjaga ketersediaan air tawar, mengurangi risiko kebakaran, serta menjadi penopang sistem transportasi. Praktik pertanian berkelanjutan juga menjaga keanekaragaman hayati yang tinggi (dengan ditemukannya ada beragam jenis spesies termasuk yang ada di dalam buku daftar merah IUCN). Keanekaragaman hayati yang tinggi secara langsung membantu polinasi kelapa yang berkontribusi pada produksi kelapa petani. Komponen sosial dan ekonomi pun ikut berkembang karena hasil pertanian kelapa mampu meningkatkan kesejahteraan dan kestabilan penghasilan. Merujuk pada hasil KDT, praktik pertanian, pengendalian kebakaran lahan, akses pangan, pengelolaan limbah, dan akses air merupakan aspek yang dinilai memadai bagi masyarakat. Sebaliknya, tata kelola lahan mendapat skor terendah karena kesulitan dalam pengurusan sertifikat lahan.

\section{UCAPAN TERIMA KASIH}

Terima kasih kepada masyarakat di Kecamatan Pulau Burung, terutama warga Desa Pulau Burung, Desa Suka Jaya, Desa Binangun Jaya, Desa Manunggal Jaya, dan Desa Bangun Harjo Jaya beserta aparatur desanya yang berperan besar dalam penelitian ini. Terima kasih kepada Sambu Group atas dukungan beserta tim ahlinya yang telah membantu 
kami dalam memahami berbagai mekanisme teknis serta pemberian data-data yang sangat bermanfaat untuk kajian pemanfaatan lahan suboptimal secara berkelanjutan.

\section{DAFTAR PUSTAKA}

Akmal A, Warto, Sariyatun. 2020. The Rapid Growth of Coconut Estates in Indragiri Hilir 1980s-1990s. Jurnal Sejarah Citra Lekha. 5(2): 121-134. https:// doi.org/10.14710/jscl.v5i2.23594

Bernard HR. 2002. Research Methods in Anthropology: Qualitative and quantitative methods. 3rd Eds. California (US): AltaMira Press.

[BPS] Badan Pusat Statistik. 2021. Berita Resmi Statistik: Hasil Sensus Penduduk 2020. Badan Pusat Statistik Indonesia. Jakarta (ID).

Buschmann C, Röder N, Berglund K, Berglund Ö, Lærke PE, Maddison M, Mander Ü, Myllys M, Osterburg B, van den Akker JJH. 2020. Perspectives on agriculturally used drained peat soils: Comparison of the socioeconomic and ecological business environments of six European regions. Land Use Policy. 90: 104181. https:// doi.org/10.1016/j.landusepol.2019.104181

Direktorat Jenderal Perkebunan. 2019. Perkebunan Statistik Perkebunan Indonesia 2017-2019. Sekretariat Direktorat Jenderal. Jakarta (ID).

Evans CD, Williamson JM, Kacaribu F, Irawan D, Suardiwerianto Y, Hidayat MF, Laurén A, Page SE. 2019. Rates and spatial variability of peat subsidence in Acacia plantation and forest landscapes in Sumatra, Indonesia. Geoderma. 338: 410-421. 2018.12.028

[FAO] Food and Agriculture Organization. 2011. Social Analysis for Agriculture And Rural Investment Projects: Field Guide. Food and Agriculture Organization of the United Nation. Roma (IT).

Fawzi NI, Qurani IZ, Darajat R. 2021. Alleviating peatland fire risk using water management trinity and community involvement. IOP Conference Series: Earth and Environmental Science. 914: 12037. https://doi.org/10.1088/1755-1315/914/1/ 012037

Fawzi NI, Rahmasary AN, Qurani IZ. 2020. Minimizing carbon loss through integrated water resource management on peatland utilization in Pulau Burung, Riau, Indonesia. E3S Web of Conferences. 200: 02019. https://doi.org/10.1051/e3sconf/2020 20002019

Hadi S. 2017. Model Pengembangan Industri Kelapa Di Provinsi Riau. In: Prosiding Seminar Nasional
Perencanaan Pembangunan Inklusif Desa-Kota. Universitas Andalas, pp. 183-190. Padang (ID).

Hooijer A, Page S, Jauhiainen J, Lee WA, Lu XX, Idris A, Anshari G. 2012. Subsidence and carbon loss in drained tropical peatlands. Biogeosciences. 9(3): 1053-1071. https://doi.org/10.5194/bg-9-10532012

Joshi, Ankur, Kale, Saket, Chandel, Satish, Pal, Dinesh. 2015. Likert Scale: Explored and Explained. British Journal of Applied Science \& Technology. 7(4): 396-403. https://doi.org/10.9734/BJAST/ $2015 / 14975$

Kang S, Post WM, Nichols JA, Wang D, West TO, Bandaru V, Izaurralde RC. 2013. Marginal Lands: Concept, Assessment and Management. Journal Agriculture Science. 5(5): 129-139. https://doi.org/ 10.5539/jas.v5n5p129

Konecny K, Ballhorn U, Navratil P, Jubanski J, Page SE, Tansey K, Hooijer A, Vernimmen R, Siegert F. 2016. Variable carbon losses from recurrent fires in drained tropical peatlands. Global Change Biology. 22(4): 1469-1480. https://doi.org/10.1111/gcb. 13186

Koop SHA, Koetsier L, Doornhof A, Reinstra O, Van Leeuwen, Brouwer S, Dieperink C, Driessen PPJ. 2017. Assessing the Governance Capacity of Cities to Address Challenges of Water, Waste, and Climate Change. Water Resources Management. 31(11): 3427-3443. https://doi.org/10.1007/s11 269-017-1677-7

Lakitan B. 2014. Inclusive and Sustainable Management of Suboptimal Lands for Productive Agriculture in Indonesia. Journal of Suboptimal Lands. 3(2): 181-192.

Lanz B, Dietz S, Swanson T. 2018. Global Economic Growth and Agricultural Land Conversion under Uncertain Productivity Improvements in Agriculture. American Journal of Agricultural Economics. 100(2): 545-569. https://doi.org/10.1093/ajae/ aax078

Pasaribu Al, Bakce D, Yusri A. 2016. The analysis of income and consumption pattern of the household coconut farmers in Pulau Burung Indragiri Hilir Municipality. JOM Faperta. 3(2): 1-12.

Preissel S, Zander P, Knierim A. 2017. Sustaining Farming on Marginal Land: Farmers' Convictions, Motivations and Strategies in Northeastern Germany. Sociologia Ruralis. 57(S1): 682-708. https://doi.org/10.1111/soru.12168

Rondhi M, Pratiwi PA, Handini VT, Sunartomo AF, Budiman SA. 2019. Agricultural Land Conversion and Food Policy in Indonesia: Historical Linkages, Current Challenges, and Future Directions. In: Mueller, L., Eulenstein, F. (Eds.), Current Trends in Landscape Research. Springer Nature Switzerland 
AG, Cham, Switzerland, pp. 631-664. https:// doi.org/10.1007/978-3-030-30069-2_29

Sambu Group. 2015. Inventarisasi Karakteristik Lahan Gambut Areal Perkebunan Kelapa dan Nanas PT RSUP di Kabupaten Indragiri Hilir Provinsi Riau. [Unpublished report]. Indragiri Hilir (IDN).

Sambu Group, [IPB] Institut Pertanian Bogor. 2019. Studi dampak sosial ekonomi terhadap masyarakat dari industri kelapa terpadu milik Sambu Group. [Unpublished report]. Bogor (IDN).

Spangenberg JH. 2005. Economic sustainability of the economy: Concepts and indicators. Int. J. Sustainable Development. 8(1/2): 47-64. https:// doi.org/10.1504/IJSD.2005.007374

Surahman A, Soni P, Shivakoti GP. 2018. Are peatland farming systems sustainable? Case study on assessing existing farming systems in the peatland of Central Kalimantan, Indonesia. Journal of Integrative Environmental Sciences. 15(1): 1-19. https://doi.org/10.1080/1943815X.2017.1412326

Tongco DC. 2007. Purposive Sampling as a Tool for Informant Selection. Ethnobotany Research \& Applications. 5: 147-158. https://doi.org/10.17348/ era.5.0.147-158

Uda SK, Hein L, Sumarga E. 2017. Towards sustainable management of Indonesian tropical peatlands. Wetlands Ecology and Management. 25: 683-701. https://doi.org/10.1007/s11273-0179544-0

Wijedasa LS, Jauhiainen J, Könönen M, Lampela M, Vasander H, Leblanc MC, Evers S, Smith TEL, Yule CM, Varkkey H, Lupascu M, Parish F, Singleton I, Clements GR, Aziz SA, Harrison ME, Cheyne S, Anshari GZ, Meijaard E, Goldstein JE, Waldron S, Hergoualc'h K, Dommain R, Frolking S, Evans CD, Posa MRC, Glaser PH, Suryadiputra N, Lubis R, Santika T, Padfield R, Kurnianto S, Hadisiswoyo P, Lim TW, Page SE, Gauci V, Van Der Meer PJ, Buckland H, Garnier F, Samuel MK, Choo LNLK, O'Reilly $P$, Warren $M$, Suksuwan $S$, Sumarga $E$, Jain A, Laurance WF, Couwenberg J, Joosten $H$, Vernimmen R, Hooijer A, Malins C, Cochrane MA, Perumal B, Siegert F, Peh KSH, Comeau LP, Verchot L, Harvey CF, Cobb A, Jaafar Z, Wösten H,
Manuri S, Müller M, Giesen W, Phelps J, Yong DL, Silvius M, Wedeux BMM, Hoyt A, Osaki M, Hirano T, Takahashi H, Kohyama TS, Haraguchi A, Nugroho NP, Coomes DA, Quoi LP, Dohong A, Gunawan H, Gaveau DLA, Langner A, Lim FKS, Edwards DP, Giam X, Van Der Werf G, Carmenta R, Verwer CC, Gibson L, Gandois L, Graham, LLB, Regalino J, Wich SA, Rieley J, Kettridge N, Brown C, Pirard R, Moore S, Capilla BR, Ballhorn U, Ho HC, Hoscilo A, Lohberger S, Evans TA, Yulianti N, Blackham G, Onrizal, Husson S, Murdiyarso D, Pangala S, Cole LES, Tacconi L, Segah H, Tonoto P, Lee JSH, Schmilewski G, Wulffraat S, Putra El, Cattau ME, Clymo RS, Morrison R, Mujahid A, Miettinen J, Liew SC, Valpola S, Wilson D, D'Arcy L, Gerding M, Sundari S, Thornton SA, Kalisz B, Chapman SJ, Su ASM, Basuki I, Itoh M, Traeholt C, Sloan S, Sayok AK, Andersen R. 2017. Denial of long-term issues with agriculture on tropical peatlands will have devastating consequences. Global Change Biology. 23: 977-982. https:// doi.org/10.1111/gcb.13516

Wijedasa LS, Sloan S, Page SE, Clements GR, Lupascu M, Evans TA. 2018. Carbon emissions from South-East Asian peatlands will increase despite emission-reduction schemes. Global Change Biology. 24(10): 4598-4613. https:// doi.org/10.1111/gcb.14340

World Bank, 2008. Adapting to Climate Change: The Case of Rice in Indonesia. The World Bank Office, Washington, D.C (USA).

World Bank, 2018a. Arable land (hectares per person) | Data. World Bank [Internet]. [diakses 17 Juni 2021]. Tersedia pada: https://data.worldbank .org/indicator/AG.LND.ARBL.HA.PC.

World Bank. 2018b. Arable land (hectares per person) - Indonesia | Data. World Bank [Internet]. [diakses 17 Juni 2021]. Tersedia pada: https:// data.worldbank.org/indicator/AG.LND.ARBL.HA.P C?locations =ID

Wösten JHM, Ritzema HP. 2001. Land and water management options for peatland development in Sarawak, Malaysia. International Peat Journal. 11: 59-66. 